\title{
Comparative study of hospitalized children with acute respiratory distress syndrome caused by SARS-CoV-2 and influenza virus
}

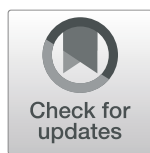

Xinghua Liu ${ }^{1 \dagger}$, Wei $\mathrm{Li}^{1 \dagger}$, Bo Zhang ${ }^{2 \dagger}$, Yan Guo ${ }^{3+}$, Zhao Hu${ }^{4}$, Cao Peng ${ }^{5}$, Xiao Lei ${ }^{6}$, Qunying Luo ${ }^{6}$, Qiong Zhang ${ }^{6}$, Wei Deng ${ }^{6}$, Juanjuan Wang ${ }^{7}$, Jianqiao Tang ${ }^{8^{*}}$, Yunqiao Li $^{6^{*}}$ and Jianying Chen ${ }^{1^{*}}$ (i)

\begin{abstract}
Background: Since the outbreak of coronavirus disease 2019 in December 2019, more than 8 million cases have occurred worldwide as of June 16, 2020. However, it is important to distinguish COVID-19 from other respiratory infectious diseases, such as influenza. Here, we comparatively described the clinical characteristics of children with COVID-19 and paediatric patients with influenza.
\end{abstract}

Methods: In this retrospective, single-centre study, we reviewed the electronic medical records of 585 paediatric patients with COVID-19 or influenza in Wuhan Children's Hospital, China. Clinical and epidemiological characteristics, laboratory findings, and clinical outcomes were comparatively analysed.

Results: The median ages were 6.96 years (IQR, 2-10.81) for children with confirmed COVID-19, 2.67 years (IQR, 1.03-15.25) for those with influenza $A$ and 3.67 years (IQR, 1.62-5.54) for those with influenza B. Fever was a symptom in 84 (34.7\%) COVID-19 cases, 132 (70.21\%) influenza A cases and 111 (74.50\%) influenza B cases. The median length of stay (LOS) was 11 (8-15) days for paediatric COVID-19 patients, 4 (3-6) days for influenza A patients and 5 (3-6) days for influenza B patients. Twenty-six (13.98\%) influenza A patients and 18 (12.59\%) influenza B patients presented with decreased white blood cell counts, while 13 (5.33\%) COVID-19 patients presented with decreased white blood cell counts. Eight (3.28\%) COVID-19 patients, 23 (12.71\%) influenza A patients and 21 (14.79\%) influenza B patients experienced lymphocytopenia. Acute cardiac injury occurred in 18 (7.29\%) COVID-19 patients, while 37 (19.68\%) influenza A and 27 (18.12\%) influenza B patients had acute cardiac injury.

(Continued on next page)

\footnotetext{
* Correspondence: tjq1996515@126.com; liyunqiao@hust.edu.cn;

unionchen@hust.edu.cn

${ }^{+}$Xinghua Liu, Wei Li, Bo Zhang and Yan Guo contributed equally to this work.

${ }^{8}$ Department of Pediatrics, Wuhan Children's Hospital, Tongji Medical College, Huazhong University of Science and Technology, Wuhan 430016,

China

${ }^{6}$ Department of Geriatrics, Union Hospital, Tongji Medical College, Huazhong

University of Science and Technology, Wuhan 430022, China

'Department of Gastrointestinal Surgery, Union Hospital, Tongji Medical

College, Huazhong University of Science and Technology, Wuhan 430022,

China

Full list of author information is available at the end of the article
}

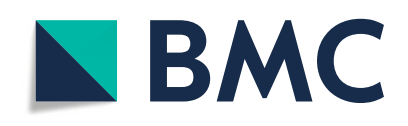

(- The Author(s). 2021 Open Access This article is licensed under a Creative Commons Attribution 4.0 International License, which permits use, sharing, adaptation, distribution and reproduction in any medium or format, as long as you give appropriate credit to the original author(s) and the source, provide a link to the Creative Commons licence, and indicate if changes were made. The images or other third party material in this article are included in the article's Creative Commons licence, unless indicated otherwise in a credit line to the material. If material is not included in the article's Creative Commons licence and your intended use is not permitted by statutory regulation or exceeds the permitted use, you will need to obtain permission directly from the copyright holder. To view a copy of this licence, visit http://creativecommons.org/licenses/by/4.0/. The Creative Commons Public Domain Dedication waiver (http://creativecommons.org/publicdomain/zero/1.0/) applies to the data made available in this article, unless otherwise stated in a credit line to the data. 
(Continued from previous page)

Conclusion: In this study, the illnesses of children with COVID-19 were demonstrated to be less severe than those of paediatric patients with influenza, and COVID-19 patients had milder illness and fewer complications.

Keywords: Children, Clinical features, COVID-19, Influenza, SARS-CoV-2

\section{Background}

Coronavirus disease 2019 (COVID-19), which first emerged in Wuhan in December 2019 and is caused by severe acute respiratory syndrome coronavirus 2 (SARSCoV-2), has rapidly spread throughout China and has spread worldwide in the past three months. As of March 28, 2020, SARS-CoV-2 has spread to most regions of China, with more than 82 thousand confirmed infections, and has spread to at least 190 countries with more than 2.7 million infected individuals. The number of COVID-19 cases in children was described as very small [1-3]. The data from the Chinese Centre for Disease Control and Prevention showed that out of 72,314 confirmed COVID-19 cases, there were 965 (1.3\%) paediatric patients [2], and in another study from the United States, $2572(1.7 \%)$ paediatric patients were reported among 149,082 confirmed cases [4]. However, with the continuous spread of SARS-CoV-2 worldwide, an increasing number of children will be infected in the future.

Recent studies have shown the primary features of paediatric patients with SARS-CoV-2 infection, and most paediatric cases appeared to be mild with symptoms of respiratory tract infection [5-7]. It has been difficult for clinicians to distinguish COVID-19 from other various respiratory diseases based on the symptoms experienced by children. Respiratory virus infections, such as influenza infection, respiratory syncytial virus infection and rhinovirus infection, are very common diseases among children, especially in the winter season [8]. Influenza was more common among children than adults, and $60 \%$ of patients were 18 years old or younger in the 2009 influenza pandemic [9]. In China, children seldom receive flu vaccination. Recently, global influenzaassociated mortality climbed to the highest level compared with that in any other flu season, and more than 240,000 influenza cases, including influenza A virus (53.5\%) and influenza B virus (46.5\%) infection, were laboratory confirmed in the United States in the past season [10]. Hospitalization and mortality rates of influenza in children were higher than those previously reported [10]. Because of the mild illness experienced by paediatric COVID-19 patients, ailing children were very easily considered to have influenza, especially in the early period of the COVID-19 epidemic, and could not be admitted to the hospital in time. Although the illnesses of most children with COVID-19 were not severe, patients with milder illness and those without symptoms might play an important role in SARS-CoV-2 transmission. It is critical to distinguish COVID-19 from influenza in children. Here, we described the comprehensive clinical characteristics of children with COVID-19 and influenza during the COVID-19 epidemic in Wuhan.

\section{Methods}

Study design and participants

A total of 585 paediatric patients, including 248 with confirmed cases of COVID-19, 188 with confirmed cases of influenza A and 149 with confirmed cases of influenza B, from Wuhan Children's Hospital were retrospectively studied. COVID-19 patients were hospitalized from January 26 to March 23, 2020, and influenza patients were admitted to the hospital from August 8, 2019, to January 26, 2020. All patients with confirmed COVID-19 recruited in this study were diagnosed by SARS-CoV-2 positivity in RT-PCR according to the World Health Organization interim guidance, and patients with confirmed influenza were diagnosed by the presence of IgM antibody against influenza virus $\mathrm{A}$ or $\mathrm{B}$. The clinical information, including treatments, discharge dates and length of stay, was monitored up to March 28, 2020.

\section{Data collection}

Data on epidemiological information, demographic characteristics, clinical manifestations, laboratory results, treatment measures and discharge date were extracted from electronic medical records. Clinical features consisted of the dates of illness onset and admission, symptoms, coexisting conditions and complications. Laboratory tests included a complete blood count, coagulation parameters, C-reactive protein, serum amyloid protein, procalcitonin, liver and renal function parameters, lactate dehydrogenase, lactate dehydrogenase isoenzyme 1 , creatine kinase and creatine kinase isoenzyme 1 . Treatment measures included oxygen therapy, antiviral agents, antibacterial agents, corticosteroids, budesonide suspension and immunomodulatory agents. All the clinical data were reviewed by team paediatricians. COVID-19 severity was classified according to experts' consensus statement for COVID-19 in children [11]. Patients with asymptomatic cases were defined as children positive for SARS-CoV-2 without manifestations of clinical symptoms or abnormal chest imaging findings. Patients with mild cases were defined as patients who had only fever, cough, pharyngeal pain, nasal 
congestion, fatigue, headache, myalgia or discomfort but no abnormal radiological findings. Patients with moderate cases were defined as children who had pneumonia on chest CT with or without fever and respiratory symptoms such as cough but did not meet the criteria for severe pneumonia. Patients with severe cases were defined as those who met any of the following criteria: (1) increased respiratory rate: $\geq 70$ times/min for those $<1$ year of age or $\geq 50$ times/min for those $\geq 1$ year of age (after ruling out the effects of fever and crying); (2) oxygen saturation < 92\%; (3) hypoxia: assisted breathing (moans, nasal flaring, and three-concave sign), cyanosis, or intermittent apnoea; (4) a disturbance of consciousness: somnolence, coma, or convulsion; and (5) food refusal or feeding difficulty, with signs of dehydration. Patients with critical cases met one of the following criteria and required intensive care unit (ICU) care: (1) respiratory failure requiring mechanical ventilation, (2) shock, or (3) other organ failure.

\section{SARS-CoV-2 nucleic acid testing}

SARS-CoV-2 nucleic acid testing was performed by the laboratory department of Wuhan Children's Hospital, and the procedure was the same as that described by $\mathrm{Lu}$ et al. [7]. In brief, nasopharyngeal or throat swabs were tested for the presence of SARS-CoV-2 nucleic acid using real-time reverse transcription polymerase chain reaction (RT-PCR). Viral nucleic acids were extracted with the High Pure Viral Nucleic Acid Kit (Zhongzhi, Wuhan, China). The primers for RT-PCR assays were as follows:

forward primer 5 '-TCAGAATGCCAATCTCCCCAAC-3'; reverse primer 5'-AAAGGTCCACCCGATACA TTGA-3'; and.

probe 5' CY5-CTAGTTACACTAGCCATCCTTACT GC-3' BHQ1.

Amplifications were performed by incubation at $50^{\circ} \mathrm{C}$ for $15 \mathrm{~min}$ and $95^{\circ} \mathrm{C}$ for $3 \mathrm{~min}$, followed by 45 cycles at $95^{\circ} \mathrm{C}$ for $15 \mathrm{~s}$ and $60^{\circ} \mathrm{C}$ for $30 \mathrm{~s}$.

\section{Statistical analysis}

Continuous variables were described as median and interquartile range (IQR) values. The comparison of medians was analysed with the Kruskal-Wallis test. Categorical variables were calculated as the percentages of patients in each category and compared using $X^{2}$ or Fisher's exact tests as appropriate. All statistical analyses were performed in SPSS software version 20.0. Two-sided $\alpha$ values of less than 0.05 indicated statistical significance.

\section{Results}

Clinical characteristics of paediatric patients with COVID19 and influenza

This study recruited 248 paediatric patients with confirmed cases of COVID-19, 188 with confirmed cases of influenza A and 149 with confirmed cases of influenza B. The median ages were 6.96 years (IQR, 2-10.81) for COVID-19 patients, 2.67 years (IQR, 1.03-15.25) for influenza A patients and 3.67 years (IQR, 1.62-5.54) for influenza B patients. The sex ratio of males to females was close to 1.5 in the three groups. Familial clustering was defined based on family infection history, which was recorded in the medical record, and familial clustering of infection occurred in 192 (77.4\%) COVID-19 patients (Table 1). Among confirmed COVID-19 cases, 39 (15.7\%) patients had coexisting conditions, while the number of children with comorbidities was 67 (35.64\%) in the influenza A group and $41(27.52 \%)$ in the influenza B group. The most common comorbidity was leukopenia; other comorbidities included hyperglobulinemia, acute lymphoblastic leukaemia, arrhythmia, tympanitis, central atrial septal defect, rhinitis, convulsion, Kawasaki disease, epilepsy, jaundice, atrial septal defect, epididymitis, acute tonsillitis, acute laryngitis, acute cervical lymphadenitis, acute gastroenteritis, anaemia, eczema, diabetic ketosis, myocarditis, thrombocytopenia, viral encephalitis, infective myositis, cerebral palsy, and thrombocytopenia (Fig. 1).

Fever and cough were the most common symptoms in the three groups, and 86 (34.7\%) COVID-19 patients presented with fever, compared to $132(70.21 \%)$ influenza A patients and 111 (74.50\%) influenza B patients, and the difference was statistically significant. For paediatric COVID-19 patients, nasal congestion, rhinorrhoea, diarrhoea and vomiting were other common symptoms, and abdominal pain and tachypnoea were less common symptoms. In the influenza groups, phlegm, asthma, sneezing, chills and vomiting were more frequently found as residual symptoms (Table 1). There were 172 (69.36\%) mild or moderate COVID-19 cases, and 4 (1.61\%) severe or critical cases; these numbers were 171 (90.96\%) and 17 (9.04\%), respectively, for influenza A and 141 (94.63\%) and 8 (5.37\%), respectively, for influenza $B$. In addition, the median duration from the onset of illness to admission was 5 (3-8) days for COVID-19 patients. The median length of stay (LOS) was $11(8-15)$ days for paediatric patients with confirmed COVID-19 cases, 4 (3-6) days for those with confirmed influenza A cases and 5 (3-6) days for those with confirmed influenza B cases (Table 1).

\section{Laboratory findings of paediatric patients infected with SARS-CoV-2 and influenza virus}

Twenty-six (13.98\%) influenza A patients and 18 (12.59\%) of influenza B patients had decreased white blood cell counts, while 13 (5.33\%) COVID-19 patients had decreased white blood cell counts. Eight (3.28\%) COVID-19 patients had lymphocytopenia, whereas 23 $(12.71 \%)$ and $21(14.79 \%)$ influenza A and influenza B 
Table 1 Clinical Characteristics of pediatric patients infected with Covid-19, Influenza A and Influenza B

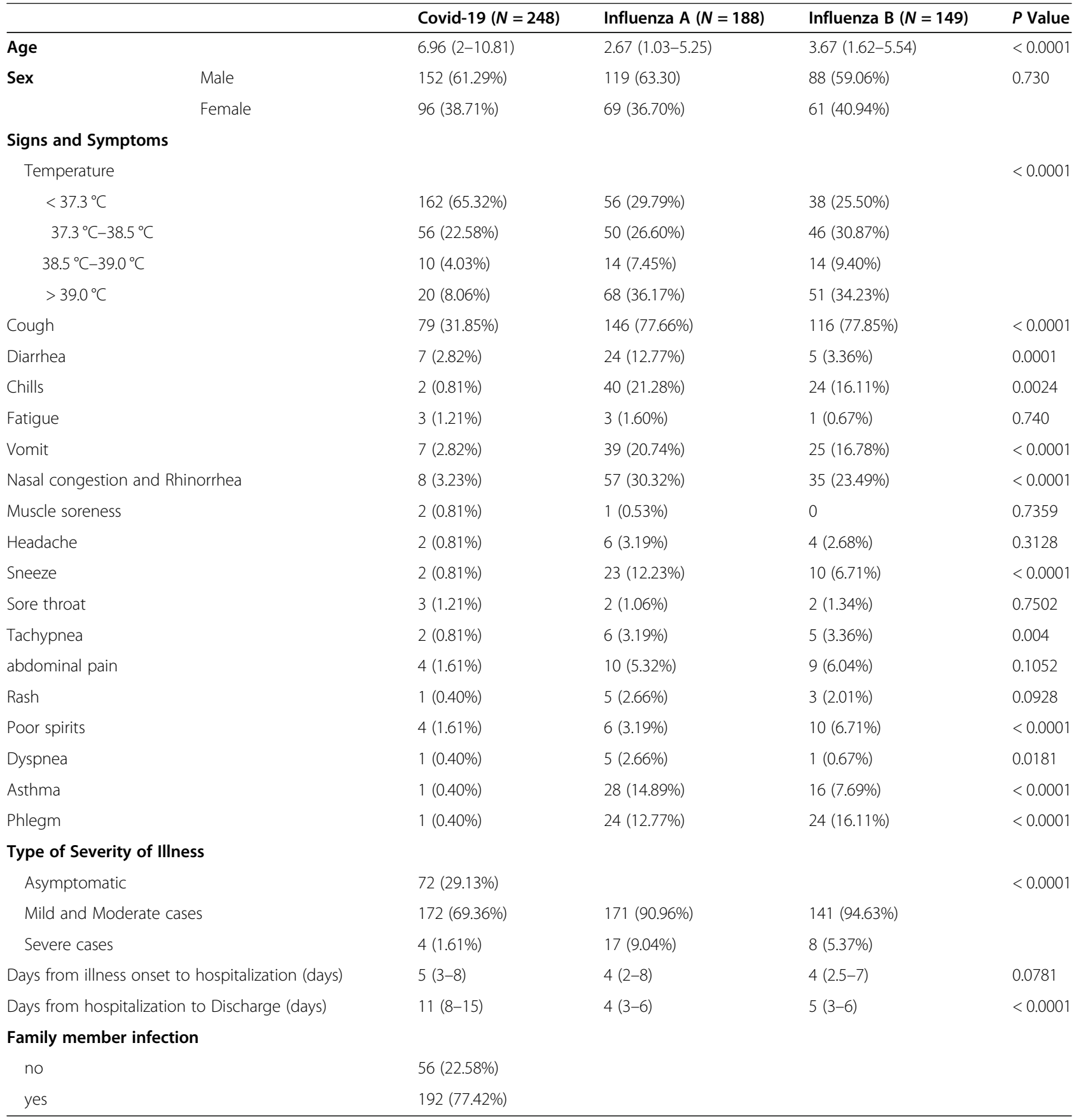

patients, respectively, had lymphocytopenia. The percentage of COVID-19 patients with abnormally elevated myocardial enzymes was less than that of influenza paediatric patients $(41.95 \%$ vs 65.06 and $62.60 \%, p<$ 0.0001 ). For inflammatory markers, the most common abnormities in the three groups were found in the erythrocyte sedimentation rate, hypersensitive C-reactive protein (hsCRP) and serum amyloid A. Serum amyloid A was increased in 13 (16.46\%) COVID-19 patients, 64 (85.33\%) influenza A patients and $46(80.70 \%)$ influenza
B patients $(p<0.0001)$, and hsCRP was abnormally elevated in 40 (18.60\%) COVID-19 patients, 93 (56.71\%) influenza A patients and 69 (40.46\%) influenza B patients $(p<0.0001)$ (Table 2).

No statistically significant difference was observed among the three groups in terms of comorbidities. SARS-CoV-2 co-infections with Mycoplasma (40.91\%), cytomegalovirus (3.03\%), and EB virus (1.99\%) were observed, and the corresponding pathogens were detected in 55.42, 3.57 and $4.12 \%$ of influenza A 


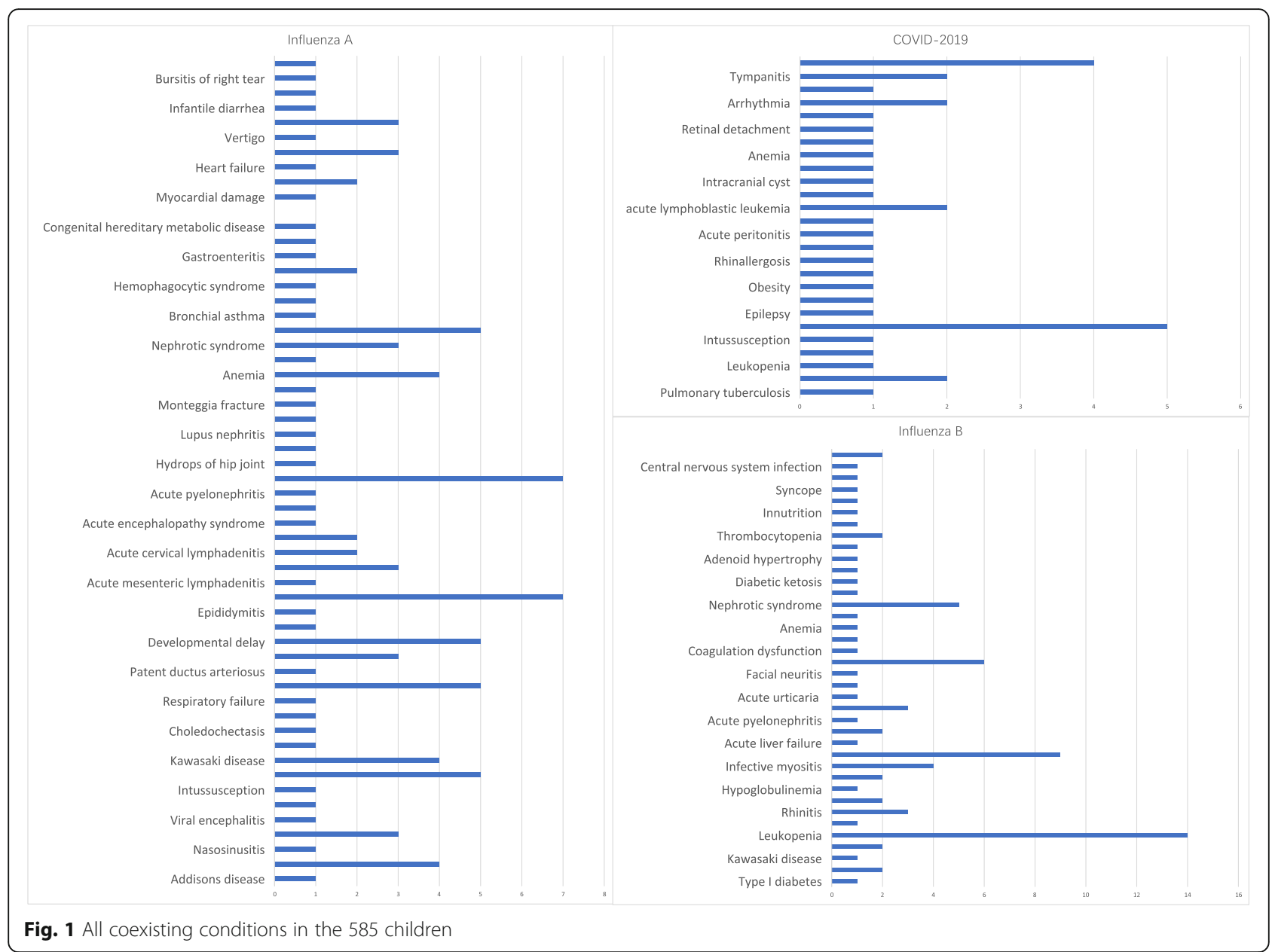

patients and in 42.00, 7.03 and $2.24 \%$ of influenza B patients, respectively. There was one case of SARSCoV-2 and influenza $A$ virus co-infection and 4 cases of SARS-CoV-2 and influenza $B$ virus co-infection (Table 2).

\section{Treatment and clinical outcome}

Common treatments, including antiviral therapy, antibiotic therapy, the use of corticosteroids and immunoglobulin, aerosol inhalation of interferon- $\alpha$ and budesonide suspension, were sympathetically applied in the studied patients. Among COVID-19 patients, $50(20.16 \%)$ were treated with antiviral drugs, 109 (43.95\%) with antibiotic therapy, 235 (94.76\%) with interferon-a, and $3(1.21 \%)$ with corticosteroids; 4 COVID-19 patients (1.61\%) received intensive care. The percentages of children receiving corticosteroids and intensive care in the influenza group were obviously higher than those in the COVID-19 group, The median length of stay in ICU for children was: 21 days for COVID-19, 8.38 days for Flu A and 13 days for Flu B. Regarding oxygen support, in the COVID-
19 group, 3 (1.21\%) children required nasal cannulation and 4 (1.61\%) children needed invasive mechanical ventilation, while 28 (14.89\%) influenza A paediatric patients and 15 (18.12\%) influenza B patients received oxygen support with nasal cannulation. The dysfunction of important organs was uncommon in COVID-19 patients. Acute cardiac injury occurred in 18 (7.29\%) COVID-19 patents, while 37 (19.68\%) influenza A and 27 (18.12\%) influenza B patients experienced acute cardiac injury. In total, only one patient in this study died, who was reported to have a severe co-existing disease, intussusception [7], and most of the patients had favourable clinical outcomes (Table 3).

\section{Discussion}

As of June 16, 2020, more than 8 million people worldwide have been infected with SARS-CoV-2, including more than 80 thousand people in China. However, approximately one thousand confirmed paediatric SARSCoV-2 infections have been reported in China [2], and knowledge of the clinical features of paediatric cases is 
Table 2 Laboratory findings of pediatric patients infected with Covid-19, Influenza A and Influenza B

\begin{tabular}{|c|c|c|c|c|c|}
\hline & & Covid-19 ( $\mathrm{N}=248)$ & Influenza A ( $\mathrm{N}=188)$ & Influenza $(\mathrm{N}=149)$ & $P$ Value \\
\hline \multicolumn{6}{|l|}{ Blood routine } \\
\hline \multirow[t]{2}{*}{ White blood cell count } & Increase & $23(9.43 \%)$ & $35(18.82 \%)$ & $27(18.88 \%)$ & 0.0001 \\
\hline & Decrease & $13(5.33 \%)$ & $26(13.98 \%)$ & $18(12.59 \%)$ & \\
\hline \multirow[t]{2}{*}{ Neutrophil count } & Increase & $33(13.52 \%)$ & $67(37.02 \%)$ & $39(27.46 \%)$ & $<0.0001$ \\
\hline & Decrease & $13(5.33 \%)$ & $13(7.18 \%)$ & $10(7.04 \%)$ & \\
\hline \multirow[t]{2}{*}{ Lymphocyte count } & Increase & $24(9.84 \%)$ & $21(11.60 \%)$ & $11(7.75 \%)$ & 0.0006 \\
\hline & Decrease & $8(3.28 \%)$ & $23(12.71 \%)$ & $21(14.79 \%)$ & \\
\hline Hemoglobin (g/L; 110.0-140.0) & & $128(120-137.75)$ & $121.5(112-128)$ & $122(113-129)$ & $<0.0001$ \\
\hline Platelet $\left(\times 10^{9} / L ; 100-320\right)$ & & $261.5(208.5-314.75)$ & $273(209.5-363.25)$ & $256(202-337)$ & 0.1707 \\
\hline Neutrophil/ Lymphocyte & & $1.06(0.61-1.69)$ & $1.22(0.64-2.97)$ & $1.31(0.68-2.46)$ & 0.0059 \\
\hline \multicolumn{6}{|l|}{ Blood biochemistry } \\
\hline Total bilirubin & Increase & 15 (6.22\%) & $11(6.32 \%)$ & $5(3.76 \%)$ & 0.5525 \\
\hline Albumin & Decrease & $12(4.98 \%)$ & $25(14.37 \%)$ & $28(13.53 \%)$ & 0.0022 \\
\hline Alanine aminotransferase & Increase & $27(11.20 \%)$ & 15 (8.62\%) & $7(5.26 \%)$ & 0.1536 \\
\hline Y-alkalinephosphatase & Increase & $12(\% 4.98)$ & $12(6.90 \%)$ & $7(5.26 \%)$ & 0.6683 \\
\hline Aspartate aminotransferase & Increase & $32(13.28 \%)$ & $43(24.71 \%)$ & $40(29.85 \%)$ & 0.0003 \\
\hline Alkaline phosphatase & Increase & $87(36.10 \%)$ & $31(17.82 \%)$ & $20(15.04 \%)$ & $<0.0001$ \\
\hline Blood urea nitrogen & Increase & $3(1.24 \%)$ & $2(1.18 \%)$ & $1(0.76 \%)$ & 0.9091 \\
\hline Creatinine & Increase & $12(4.98 \%)$ & 0 & $3(2.29 \%)$ & 0.0094 \\
\hline Lactate dehydrogenase $\mathrm{L}$ & Increase & $54(22.88 \%)$ & $74(44.58 \%)$ & $58(44.27 \%)$ & $<0.0001$ \\
\hline Lactate dehydrogenase isozyme -1 & Increase & $64(27.12 \%)$ & $74(44.58 \%)$ & $59(45.04 \%)$ & $<0.0001$ \\
\hline Creatine kinase & Increase & $15(6.07 \%)$ & $15(8.02 \%)$ & $14(9.46 \%)$ & 0.4487 \\
\hline Creatine kinase isoenzyme $-\mathrm{MB}$ & Increase & $99(41.95 \%)$ & $108(65.06 \%)$ & $82(62.60 \%)$ & $<0.0001$ \\
\hline \multicolumn{6}{|l|}{ Infection biomarkers } \\
\hline Hypersensitive troponin $T$ & Increase & $7(5.93 \%)$ & $6(22.22 \%)$ & $2(15.38 \%)$ & 0.0252 \\
\hline Ferroprotein & Increase & $4(2.82 \%)$ & $6(8.11 \%)$ & $7(12.50 \%)$ & 0.0298 \\
\hline Serum amyloid $A$ & Increase & $13(16.46 \%)$ & $64(85.33 \%)$ & $46(80.70 \%)$ & $<0.0001$ \\
\hline Erythrocyte sedimentation rate & Increase & $13(22.81 \%)$ & $46(56.79 \%)$ & $28(51.85 \%)$ & $<0.0001$ \\
\hline Hypersensitive C-reactive protein & Increase & $40(18.60 \%)$ & $93(56.71 \%)$ & $69(40.64 \%)$ & $<0.0001$ \\
\hline Procalcitonin & Increase & $5(2.05 \%)$ & $4(2.23 \%)$ & $1(0.70 \%)$ & 0.5328 \\
\hline D-Dimer & Increase & $25(13.81 \%)$ & $22(45.83 \%)$ & $19(52.77 \%)$ & $<0.0001$ \\
\hline \multicolumn{6}{|l|}{ Others pathogen infections } \\
\hline Mycoplasma & & $45(40.91 \%)$ & $46(55.42 \%)$ & $21(42.00 \%)$ & 0.1089 \\
\hline Cytomegalovirus & & $4(3.03 \%)$ & $6(3.57 \%)$ & $9(7.03 \%)$ & 0.2296 \\
\hline Eb virus & & $3(1.99 \%)$ & $7(4.12 \%)$ & $3(2.24 \%)$ & 04561 \\
\hline Influenza A & & $1(0.91 \%)$ & & & \\
\hline Influenza B & & $4(3.63 \%)$ & & & \\
\hline Legionella pneumoniae & & 0 & $1(1.20 \%)$ & 0 & 0.3799 \\
\hline
\end{tabular}

limited. Here, we comprehensively and comparatively characterized the clinical features of children with COVID-19 and those with influenza A or influenza B in Wuhan during the COVID-19 epidemic.

Our data demonstrated that the epidemiological profiles of paediatric COVID-19 patients were different from those of paediatric influenza patients. The age of children with COVID-19 was older than that of children with influenza. Our analysis showed that $46(55.46 \%)$ influenza A patients and 21 (42.00\%) influenza B patients were co-infected with Mycoplasma, 6 (3.54\%) influenza A patients and 9 (7.03\%) influenza B patients were co-infected with cytomegalovirus, 
Table 3 Complications, Treatment and Outcome in pediatric patients infected with Covid-19, Influenza A and Influenza B

\begin{tabular}{|c|c|c|c|c|}
\hline & $\begin{array}{l}\text { Covid-19 } \\
(\mathrm{N}=248)\end{array}$ & $\begin{array}{l}\text { A influenza } \\
(\mathrm{N}=188)\end{array}$ & $\begin{array}{l}\text { B influenza } \\
(\mathrm{N}=149)\end{array}$ & P Value \\
\hline \multicolumn{5}{|l|}{ Treatment } \\
\hline Antiviral therapy & $50(20.16 \%)$ & $86(45.74 \%)$ & $65(43.62 \%)$ & $<0.0001$ \\
\hline Antibiotic therapy & $109(43.95 \%)$ & $166(88.30 \%)$ & $143(95.97 \%)$ & $<0.0001$ \\
\hline Use of corticosteroid & $3(1.21 \%)$ & $23(12.23 \%)$ & $13(8.72 \%)$ & 0.0001 \\
\hline Interferon a & $235(94.76 \%)$ & $22(11.70 \%)$ & $13(8.72)$ & $<0.0001$ \\
\hline Immunoglobulin & $1(0.40 \%)$ & $4((2.13 \%)$ & $5(3.36 \%)$ & 0.0774 \\
\hline ICU & $4(1.61 \%)$ & $14(7.45 \%)$ & $4(2.68 \%)$ & 0.0043 \\
\hline \multicolumn{5}{|l|}{ Oxygen support } \\
\hline Nasal cannula & $3(1.21 \%)$ & $28(14.89 \%)$ & $15(10.07 \%)$ & $<0.0001$ \\
\hline Invasive mechanical ventilation & $4(1.61 \%)$ & $6(3.19 \%)$ & $2(1.34 \%)$ & 0.4164 \\
\hline \multicolumn{5}{|l|}{ Complications } \\
\hline Cardiac injury & $18(7.26 \%)$ & $37(19.68 \%)$ & $27(18.12 \%)$ & 0.0002 \\
\hline Liver dysfunction & $13(5.24 \%)$ & $7(3.72 \%)$ & $3(2.01 \%)$ & 0.2725 \\
\hline Acute gastroenteritis & $5(2.02 \%)$ & $5(2.66 \%)$ & $1(0.67 \%)$ & 0.4017 \\
\hline Neutropenia & 0 & $8(4.26 \%)$ & $9(6.04 \%)$ & 0.0010 \\
\hline Lung injury & 0 & $6(3.19 \%)$ & 0 & 0.0017 \\
\hline Renal injury & $2(0.81 \%)$ & $1(0.53 \%)$ & 0 & 0.5520 \\
\hline MODS & $2(0.81 \%)$ & $2(1.06 \%)$ & 0 & 0.4769 \\
\hline \multicolumn{5}{|l|}{ Clinical outcome } \\
\hline Discharge or in hospital & 247 & 188 & 149 & \\
\hline Death & 1 & 0 & 0 & \\
\hline
\end{tabular}

and 7 (4.12\%) influenza A patients and 3 (2.24\%) influenza $\mathrm{B}$ patients were co-infected with Epstein-Barr virus. The distribution of these common pathogens in influenza patients was identical to that in COVID-19 patients. Few COVID-19 patients were co-infected with influenza. This might indicate that other pathogen infections were independent of SARS-CoV-2 infection. Similar to influenza [10, 12], SARS-CoV-2 exhibits prevalent human-to-human transmission through close contact; $77.4 \%$ of children had a history of household contact, and the remaining (22.6\%) COVID-19 patients had an unknown exposure history and might have acquired community infection.

In this study, more than half of the paediatric COVID19 patients were diagnosed with mild or moderate cases, and $1.61 \%$ of cases were severe, which was significantly less than the number of severe influenza cases. Additionally, the severity of COVID-19 in children was obviously different from that in adult patients. Among adult COVID-19 patients, 20 to $25 \%$ were admitted to the ICU, $5 \%$ had critical cases, and 3 to $4 \%$ died [13-15]. This might indicate that the pathogenicity of SARS-CoV-2 in children resembled that of two other severe-respiratorydisease-associated coronaviruses, severe acute respiratory syndrome coronavirus (SARS-CoV) and Middle East respiratory syndrome coronavirus (MERS-CoV), and children with SARS or MERS also suffered much less than adults with these illnesses [16, 17].

Fever and cough were the predominant symptoms at the onset of illness for both COVID-19 and influenza paediatric patients. Fever was identified in $34.68 \%$ of the COVID-19 cases, $70.21 \%$ of the influenza A cases and in $74.50 \%$ of the influenza B cases. Cough was present in $31.85 \%$ of COVID-19 cases, which was more than half of that in influenza cases. Although COVID-19 patients were less likely to exhibit symptoms and signs of respiratory infection, such as fever, cough, chills, sneezing, nasal congestion and rhinorrhoea, but more likely to present gastrointestinal symptoms, including vomiting, diarrhoea, dyspnoea and abdominal pain, it is not easy to differentiate COVID-19 from influenza in children on the basis of symptoms. Therefore, it might be necessary to closely monitor and examine child contacts.

The limitation of this study is that symptom-free children in the COVID-19 group were routinely screened out on the basis of close child contacts, but influenza patients were admitted to the hospital after the appearance of symptoms. This would upwardly bias the divergences of the COVID-19 group from the influenza groups. Another limitation is that COVID-19 patients were diagnosed on the basis of SARS-CoV-2 positivity in RT-PCR, but 
influenza patients were diagnosed on the basis of the presence of IgM antibody against influenza A virus or influenza B virus, which did not allow the comparison of COVID-19 and influenza cases at similar stages of disease duration. Partial information of the COVID-19 patients in this hospital centre was reported by other groups [7, 18, 19]. However, we independently described the characteristics of COVID-19 patients from different aspects. In addition, the oxygen saturation level was not detected in every patient. Only patients with moderate, severe and critical cases had oxygen saturation level data; therefore, we did not analyse these data. We could not obtain an accurate duration of oxygen support; therefore, we did not analyse these data or show this information in the tables.

\section{Conclusions}

Similar to adult patients [20], there were many differences in clinical presentations between paediatric COVID-19 and influenza. Paediatric patients with COVID-19 had a lower severity of illness than children with influenza. The clinical presentations and outcomes were more favourable in paediatric COVID-19 patients than in paediatric influenza patients.

\section{Abbreviations}

IQR: Interquartile Range; LOS: Length of Stay; SARS-CoV: Severe Acute Respiratory Syndrome Coronavirus; SARS-CoV-2: Severe Acute Respiratory Syndrome Coronavirus 2; MERS-CoV: Middle East Severe Acute Respiratory Syndrome Coronavirus; hsCRP: Hypersensitive C-reactive protein; ICU: Intensive Care Unit; RT-PCR: Real-time reverse transcription Polymerase Chain Reaction; MODS: Multiple Organ Dysfunction Syndrome; Flu: Influenza; IgM: Immunoglobulin M

\section{Acknowledgements}

None.

\section{Authors' contributions}

Drs JC, YL and JT had full access to all of the data in the study and take responsibility for the integrity of the data and the accuracy of the data analysis. Concept and design: BZ and JC. Acquisition, analysis, or interpretation of data: XL, WL, XL (Xiao Lei), QL, QZ, CP, and JW. Drafting of the manuscript: $X L$ and $W L$. Critical revision of the manuscript for important intellectual content: JC. Statistical analysis: $X \mathrm{~L}$ and $Y G$. Administrative, technical, or material support: JT. Supervision: JT, YL, and JC. The author(s) read and approved the final manuscript.

\section{Funding}

This work was supported by the Nature Science Foundation of Hubei Province (2017CFB633 to Dr. Yunqiao. Li; 2017CFB412 to Dr. Jianying. Chen) for the design of the study and analysis, and interpretation of data. and the Health Research Project of Hubei Province (WJ2019M166 to Dr. Xingua. Liu) for collection of data and writing the manuscript.

\section{Availability of data and materials}

The data were used under license for the current study, and so are not publicly available.

\section{Declarations}

\section{Ethics approval and consent to participate}

This study was approved by the Ethics Committee.

of Tongji Medical College, Huazhong University of Science and Technology and followed the Declaration of Helsinki. Oral consent was obtained from the guardians of the patients. The Ethics Committee approved obtaining verbal consent over written consent.

\section{Consent for publication}

All authors have read and approved the manuscript, and agree to publishment.

\section{Competing interests}

No competing interests.

\section{Author details}

${ }^{1}$ Department of Gastrointestinal Surgery, Union Hospital, Tongji Medical College, Huazhong University of Science and Technology, Wuhan 430022, China. ${ }^{2}$ Department of Thyroid and Breast Surgery, Union Hospital Affiliated to Tongji Medical College, Huazhong University of Science and Technology, Wuhan 430022, China. ${ }^{3}$ Wuhan Center for Disease Control and Prevention, Wuhan 430024, China. ${ }^{4}$ Department of Rheumatology and Immunology, Wuhan Children's Hospital, Tongji Medical College, Huazhong University of Science and Technology, Wuhan 430016, China. ${ }^{5}$ Department of Emergency Medicine, Union Hospital, Tongji Medical College, Huazhong University of Science and Technology, Wuhan 430022, China. 'Department of Geriatrics, Union Hospital, Tongji Medical College, Huazhong University of Science and Technology, Wuhan 430022, China. ${ }^{7}$ Department of Rheumatology and Immunology, Anhui Provincial Children's Hospital, Hefei 230032, China. ${ }^{8}$ Department of Pediatrics, Wuhan Children's Hospital, Tongji Medical College, Huazhong University of Science and Technology, Wuhan 430016, China

Received: 26 May 2020 Accepted: 14 April 2021

Published online: 04 May 2021

\section{References}

1. Zhu N, Zhang D, Wang W, Li X, Yang B, Song J, et al. A novel coronavirus from patients with pneumonia in China, 2019. N Engl J Med. 2020;382(8): 727-33. https://doi.org/10.1056/NEJMoa2001017.

2. Wu Z, McGoogan JM. Characteristics of and important lessons from the coronavirus Disease 2019 (COVID-19) outbreak in China: summary of a report of 72314 cases from the Chinese Center for Disease Control and Prevention. JAMA. 2020;323(13):1239-42. https://doi.org/10.1001/jama.2020.2648.

3. Chen N, Zhou M, Dong X, Qu J, Gong F, Han Y, et al. Epidemiological and clinical characteristics of 99 cases of 2019 novel coronavirus pneumonia in Wuhan, China: a descriptive study. LANCET. 2020;395(10223):507-13. https:// doi.org/10.1016/S0140-6736(20)30211-7

4. Coronavirus Disease 2019. In children - United States, February 12-April 2, 2020. MMWR Morb Mortal Wkly Rep. 2020;69(14):422-6.

5. Cai J, Xu J, Lin D, Yang Z, Xu L, Qu Z, et al. A case series of children with 2019 novel coronavirus infection: clinical and epidemiological features. Clin Infect Dis. 2020.

6. Liu W, Zhang Q, Chen J, Xiang R, Song H, Shu S, et al. Detection of Covid19 in children in early January 2020 in Wuhan, China. N Engl J Med. 2020.

7. Lu X, Zhang L, Du H, Zhang J, Li YY, Qu J, et al. SARS-CoV-2 infection in children. N Engl J Med. 2020;382(17):1663-5. https://doi.org/10.1056/NEJMc2005073.

8. Ruuskanen O, Lahti E, Jennings LC, Murdoch DR. Viral pneumonia. LANCET. 2011;377(9773):1264-75. https://doi.org/10.1016/S0140-6736(10)61459-6.

9. Cauchemez S, Donnelly CA, Reed C, Ghani AC, Fraser C, Kent CK, et al. Household transmission of 2009 pandemic influenza a (H1N1) virus in the United States. N Engl J Med. 2009;361(27):2619-27. https://doi.org/10.1056/ NEJMoa0905498.

10. Weekly U.S. Influenza Surveillance Report | CDCminusSASstats. In., vol. 2020: Everything you need to know about the flu illness, including symptoms, treatment and prevention.

11. Feng Y, Ling Y, Bai T, Xie Y, Huang J, Li J, et al. COVID-19 with different severities: a multicenter study of clinical features. Am J Respir Crit Care Med. 2020;201(11):1380-8. https://doi.org/10.1164/rccm.202002-0445OC.

12. Takashita E, Ichikawa M, Morita H, Ogawa R, Fujisaki S, Shirakura M, et al Human-to-human transmission of influenza a(H3N2) virus with reduced susceptibility to Baloxavir, Japan, February 2019. Emerg Infect Dis. 2019; 25(11):2108-11. https://doi.org/10.3201/eid2511.190757.

13. Al-Tawfiq JA, Kattan RF, Memish ZA. Middle East respiratory syndrome coronavirus disease is rare in children: an update from Saudi Arabia. World Clin Pediatr. 2016;5(4):391-6. https://doi.org/10.5409/wjcp.v5.i4.391. 
14. Guan WJ, Ni ZY, Hu Y, Liang WH, Ou CQ, He JX, et al. Clinical characteristics of coronavirus Disease 2019 in China. N Engl J Med. 2020;382(18):1708-20. https://doi.org/10.1056/NEJMoa2002032.

15. Hon KL, Leung CW, Cheng WT, Chan PK, Chu WC, Kwan YW, et al. Clinical presentations and outcome of severe acute respiratory syndrome in children. LANCET. 2003;361(9370):1701-3. https://doi.org/10.1016/S0140-6736(03)13364-8.

16. Memish ZA, Al-Tawfiq JA, Assiri A, AlRabiah FA, Al HS, Albarrak A, et al. Middle East respiratory syndrome coronavirus disease in children. Pediatr Infect Dis J. 2014;33(9):904-6. https://doi.org/10.1097/INF.0000000000000325.

17. Thabet F, Chehab M, Bafaqih H, Al MS. Middle East respiratory syndrome coronavirus in children. SAUDI MED J. 2015;36(4):484-6. https://doi.org/10.1 5537/smj.2015.4.10243

18. Xiong XL, Wong KK, Chi SQ, Zhou AF, Tang JQ, Zhou LS, et al. Comparative study of the clinical characteristics and epidemiological trend of 244 COVID19 infected children with or without Gl symptoms. GUT. 2020:gutjnl-2020321486. https://doi.org/10.1136/gutjnl-2020-321486.

19. Zeng L, Xia S, Yuan W, Yan K, Xiao F, Shao J, et al. Neonatal early-onset infection with SARS-CoV-2 in 33 neonates born to mothers with COVID-19 in Wuhan, China. JAMA PEDIATR. 2020.

20. Tang X, Du RH, Wang R, Cao TZ, Guan LL, Yang CQ, et al. Comparison of hospitalized patients with ARDS caused by COVID-19 and H1N1. CHEST. 2020;158(1):195-205. https://doi.org/10.1016/j.chest.2020.03.032.

\section{Publisher's Note}

Springer Nature remains neutral with regard to jurisdictional claims in published maps and institutional affiliations.

Ready to submit your research? Choose BMC and benefit from:

- fast, convenient online submission

- thorough peer review by experienced researchers in your field

- rapid publication on acceptance

- support for research data, including large and complex data types

- gold Open Access which fosters wider collaboration and increased citations

- maximum visibility for your research: over $100 \mathrm{M}$ website views per year

At $\mathrm{BMC}$, research is always in progress.

Learn more biomedcentral.com/submissions 